\title{
Chyluria associated with bronchial carcinoma
}

\author{
A. H. MORICE \\ M.A., M.B., B.Chir. \\ J. R. WooD \\ B.Sc., M.B. B.S.
}

Department of Medicine, Brompton Hospital, London, S.W.3

\begin{abstract}
Summary
Chylous pleural effusion, though not chyluria, is a recognized association of carcinoma of the bronchus. A case of chyluria associated with squamous bronchial carcinoma is reported. Chyluria in this patient was successfully treated by dietary modification.
\end{abstract}

\section{Introduction}

Descriptions of chyluria - the passage of milky white urine - have been recorded since the time of Hippocrates (Foesius, 1665). The condition, although not uncommon in the Far East, is rare in Britain. On a world-wide basis, it most commonly results from filarial worm infection of lymphatics. Non-parasitic causes of chyluria include congenital malformations of the thoracic duct, trauma and tuberculosis (Servelle et al., 1963; Lazarus and Marks, 1946). Despite the frequency of bronchial carcinoma, the authors have been unable to find any report of its association with chyluria. Such an instance, in a patient whose chyluria responded to medical treatment, is reported.

\section{Case report}

A 55-year-old Negro heating engineer with a cough productive of brown sputum presented having felt generally unwell for 6 months with recent anorexia and weight loss. In the 2 weeks preceding admission, he developed increased cough with an episode of cough syncope, ill-defined central chest pain, and a hoarse voice. He had smoked 20 cigarettes/day for many years. Born in British Guiana, he had lived in England for 30 years, having travelled abroad on one occasion to Liberia 14 years previously.

He was thin, had clubbed fingers and a raised non-pulsatile jugular venous pressure. Examination of the respiratory system revealed stridor with a hyperinflated chest, but no other abnormalities. His chest radiograph showed a $7-\mathrm{cm}$ lobulated mass at the right hilum. The left hilum was also enlarged. Sputum cytology revealed squamous cell carcinoma.

$\mathrm{He}$ was treated by radiotherapy to both the mediastinum and right supraclavicular fossa, receiving $200 \mathrm{rad}$ daily to each side, totalling $8000 \mathrm{rad}$. His treatment, which resulted in marked clinical and radiographic improvement, was complicated by radiation-induced dysphagia. On discharge, he remained well for 14 weeks.

He was readmitted with a 2-week history of milky urine and intermittent urinary retention without other urinary tract symptoms. Micturition had been previously normal with no past history of renal or urinary tract disease. His urine contained clots varying in colour from white to cream and it coagulated on standing, giving the appearance of blancmange. Micturition was difficult, with episodes of acute retention occurring mainly at night. These were relieved by suprapubic pressure, resulting in clot expulsion.

\section{Investigations \\ Urine}

A diagnosis of chyluria was confirmed by urine analysis. The urine contained plasma proteins, fat globules, and triglycerides. More than 100 erythrocytes and 15 leucocytes $/ \mathrm{mm}^{3}$ were seen on microscopy. Repeated urine cultures showed no significant growth. The transit of a lipid soluble dye from ingestion to appearance in the urine was 175 minutes as estimated by oral administration of Sudan III in $30 \mathrm{ml}$ of arachis oil.

\section{Haematology}

$\mathrm{Hb} 12.1 \mathrm{~g} / \mathrm{dl}$; MCV $90 \mu^{3}$; WBC ranged from 9.2 to $10.6 \times 10^{9} / 1$; a differential count showed 86 to $88 \%$ neutrophils with 0 to $2 \%$ eosinophils. Microfilariae were absent from nocturnal blood samples. The ESR ranged from 60 to $89 \mathrm{~mm} / \mathrm{hr}$ (Westergren).

\section{Biochemistry}

Plasma urea, electrolytes, calcium, phosphate and creatinine were within normal limits. The total serum protein fell from 86 to $52 \mathrm{~g}$ and the serum albumin from 34 to $11 \mathrm{~g} / 1$ between the first and second 
admissions. Other liver function tests remained normal.

\section{Immunology}

Filarial fluorescent antibody test and a schistosomal complement fixation test were negative.

\section{Radiology}

Chest radiographs on his second admission showed a marked reduction in size of the right upper lobe mass with some linear shadowing (possibly due to post-radiation fibrosis) extending from the hilum to both apices. Cavitation was present in the left suprahilar region.

An i.v. urogram showed no evidence of renal tract calcification. The kidneys, pelvicalyceal system and ureters were normal. There was slight elevation of the bladder base consistent with mild prostatic enlargement. The bladder emptied satisfactorily on micturition.

\section{Subsequent course}

A diagnosis of chyluria secondary to bronchial carcinoma was made. Treatment of chyluria consisted of a low fat diet ( $20 \mathrm{~g}$ fat daily) supplemented by $30 \mathrm{ml}$ of medium-chain triglyceride (MCT) oil with each meal. On this regime, the chyluria resolved within 3 days. The patient was given appropriate dietary instructions and discharged home.

Domestic circumstances prevented rigorous compliance with the advised treatment and chyluria gradually returned until readmission became necessary 5 weeks later. His chyluria again responded within 4 days to reinstitution of the above regime. MCT oil was withdrawn after the first week owing to troublesome diarrhoea. On the low fat diet alone, he remained free of chyluria until death 9 weeks later.

A post-mortem examination revealed squamous carcinoma of the bronchus with metastases in the liver and heart. The upper lobes of both lungs were infiltrated with necrotic tumour, more markedly so on the right. Infiltration of the mediastinum was extensive with involvement of the tracheal wall and obstruction of the superior vena cava. The thoracic duct was obstructed by tumour mass behind the arch of the aorta. Examination of the urinary tract revealed a solitary metastasis in the upper pole of the right kidney.

The pelvicalyceal system, ureters and bladder were normal with enlargement of the middle lobe of the prostate.

\section{Discussion}

Non-parasitic chyluria is a rare phenomenon which, by virtue of its dramatic appearance, has been recorded in the medical literature since ancient times. In 1946, Lazarus and Marks comprehensively reviewed the literature and found only a single case associated with a neoplasm. This patient reported by Le Dantec in 1923 (Lazarus and Marks, 1946) had carcinoma of the kidney. The authors' search of the os subsequent literature has revealed no further cases? of chyluria in association with carcinoma.

Ackerman in 1863 (Lazarus and Marks, 1946) $\frac{\overline{\bar{S}}}{\overline{6}}$ postulated that chyluria resulted from obstruction $\propto$ between the lacteals of the small intestine and the termination of the thoracic duct in the neck. This would result in an increase of lymphatic pressure, $\stackrel{\circ}{\circ}$ lymph stasis, retrograde flow of lymph with lym- $\vec{\omega}$ phatic varices and subsequent rupture of lymph $\stackrel{\omega}{\omega}$ vessels in the urinary tract, a theory which was: accepted for many years. Koehler and others (1968) 3 . studied 15 cases of chyluria by lymphangiography or and found 13 to have normal thoracic ducts. Thoracic duct abnormalities can, however, cause of chyluria (Servelle et al., 1963).

In the present case, lymphangiography was not $\stackrel{\mathscr{\omega}}{\omega}$ performed owing to the experience of Hashim et al. 옥 (1964) that this procedure may result in a recurrence of chyluria persisting for as long as 6 months.

A modification of the Sudan dye test (Johnston, $\frac{0}{3}$

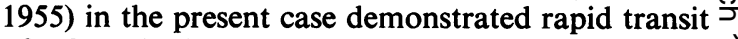
of a fat soluble dye between the gastrointestinal ang $\vec{\oplus}$ urinary tracts. The precise anatomical location $\stackrel{\infty}{\rightarrow}$ the abnormal communication was not determin

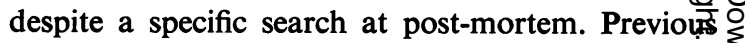
studies suggest that it may occur at any level (i.e. kidney, renal pelvis or bladder). Whether or not the intrarenal metastasis could provide an effective $\frac{\circ}{\varnothing}$ communication is not known.

The successful management of chyluria has been $\overline{\overrightarrow{0}}$ reported using both surgical and conservative treat- 3 ment. In the present case, associated with advanced malignancy, a conservative management was clearly indicated. Hampton (1920) successfully showed that chyluria could be abolished with a fat-free diet. More recently, Hashim et al. (1964) modified this 3 regime by total substitution of dietary fat with medium-chain triglycerides which are adsorbed directly into the portal venous blood. The latter substitution was initially successful in the present patient. However, administration of medium-chain $\frac{7}{0}$ triglyceride oil was associated with troublesome diarrhoea, presumably owing to the cathartic effect of of its constituent fatty acids.

\section{Acknowledgment}

We are grateful to Dr K. M. Citron for permission to report the above case.

\section{References}

Foesius, A. (1665) The Eight Sections of Hippocrates' Aphorisms Reviewed and Rendered into English According to the Translation of Antonius Foesius. Crofts, London. 
Hampton, H.H. (1920) A case of non-parasitic hematochyluria. Johns Hopkins Hospital Bulletin, 31, 20.

Hashim, S.A., Hartvig, B.R., Babayan, V.K. \& Van Italie, T.B. (1964) Treatment of chyluria and chylothorax with medium-chain triglyceride. New England Journal of Medicine, 270, 756.

Johnston, D.W. (1955) Chyluria: case report and review of literature. Annals of Internal Medicine, 42, 931.

Kọhler, P.R., Chiang, T.C., Lin, C.T., Chew, K.C. \&
Chew, K.Y. (1968) Lymphography in chyluria. American Journal of Roentgenology, 102, 455.

LAZARUS, J.A. \& MARKs, M.S. (1946) Non-parasitic chyluria with special reference to traumatic chyluria. Journal of Urology, 56, 246.

Servelle, M., Turiaf, J., Rouffilange, H., Scherer, G., Perrot, H., Frentz, F. \& Turpyn, H. (1963) Chyluria in abnormalities of thoracic duct. Surgery, 54, 536. 